American J. of Engineering and Applied Sciences 5 (1): 25-28, 2012

ISSN 1941-7020

(C) 2014 Ghasemi and Akbarzadeh, This open access article is distributed under a Creative Commons Attribution

(CC-BY) 3.0 license

\title{
Calibration Coefficients for \\ Residual Stress Measurement in Composite Materials Using Finite Element Method
}

\author{
Ghasemi, A.G. and M. Akbarzadeh \\ Depatment of Mechanical Engineering, University of Semnan, Semnan, Iran
}

\begin{abstract}
Problem statement: Since the residual stresses can cause a scienificant reduction in strength of the mechanical components, having a semi-destructive measuring method that would predict and model theses stresses would be an advantage. The hole drilling method has been used, by many researches, for measurement of the residual stresses in different materials. In this article, the finite element method is used to simulate the hole drilling method. Approach: The calibration factors required for measuring the residual stresses in composite materials are performed using a finite element procedure instead of experimental techniques. In this approach, the elements within the whole boundary are firstly removed from the finite element model of the specimen. Then, the average strains released around the whole area are measured using a there-strain gage rosette located near the whole boundary. Results: The calibration factors which are used to convert the released strains to residual stresses are obtained by the hole drilling method. The results for an orthotropic unidirectional ply made of glass/epoxy are presented. Conclusion: The compliance factors are represented as a $3 \times 3$ matrix for the orthotropic material. The results obtained from the finite element method are compared with the analytical solution method. A good agreement between the results shows the reliability of the numerical method presented in this study.
\end{abstract}

Key words: Residual stresses, calibration factors, hole drilling method, composites materials, finite element method, released strains

\section{INTRODUCTION}

The hole drilling method is a widely used technique for measuring residual stresses in laminated composites. This is the only method for measurement of residual stresses that is accepted as an (ASTM E83708e1, 1996). The hole drilling method for measuring residual stresses was presented in 1934 by (Mathar, 1934). In 1968, (Bert and Thompson, 1968) and in 1987 (Prasad and Prabhakaran, 1987) extended the hole drilling method for orthotropic materials. Schajer and Yang (1994) that the development of the central hole drilling method for orthotropic materials by (Prasad and Prabhakaran, 1987) is not valid. They presented a different method for orthotropic materials with any degree of orthotropy. They developed a table of calibration constants for orthotropic materials. Shokrieh and Ghasemi (2007) obtained calibration factors in points of rosette strain gage by exact solution of equation of stress and strain around hole in orthotropic composite materials.

Residual stresses in composites are produced during the manufacturing process due to mismatch of the coefficient of thermal expansion of fibers and matrix. Cure temperature plays a key role in determining the values of the residual stresses. The magnitudes of these stresses depend on the ply lay-up, material properties of the unidirectional ply and manufacturing processes. These residual stresses reduce the efficiency of structures and can cause matrix cracking, fiber breakage and delaminating. Therefore, they reduce the ultimate strength of structures. In the hole drilling method a rosette strain gage is mounted to a specimen containing residual stresses. There strain gages locate in 0,90 and $225^{\circ}$. To measure a residual stress, a circular hole is drilled at the geometrical center of the rosette to a depth slightly greater than the whole diameter. This hole locally relieves the stresses in the surrounding material. Finally, the engendered strain can be measured by the three strain gages.

In this study, we use the finite element method for calculation of calibration factors. The results obtained from the numerical method are compared with the analytical solution method. An acceptable agreement between the results shows the reliability of the numerical method presented in this study.

Corresponding Author: Ghasemi A.G., Depatment of Mechanical Engineering, Faculty of Mechanical Engineering, University of Semnan, Semnan, Iran 

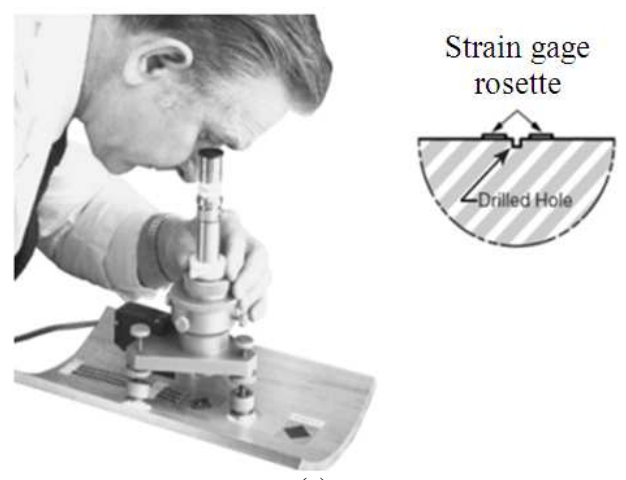

(a)

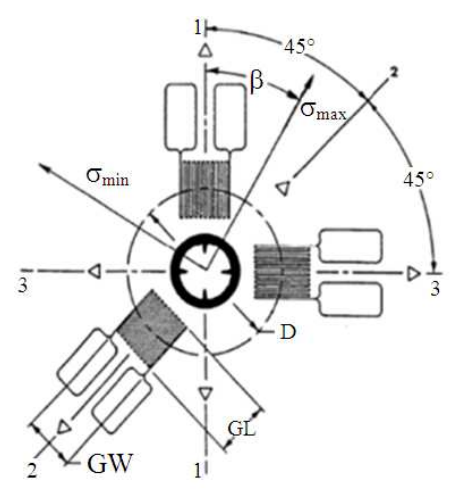

(b)

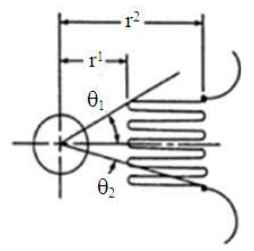

Fig. 1: (a) The central hole drilling apparatus and (b) Rosette strain gage (adapted from (Schajer and Yang, 1994)

\section{MATERIALS AND METHODS}

Calibration factors for isotropic materials: For isotropic materials the released strains measured by each strain gage, located at the angle of $\theta$ with respect to the $\mathrm{x}$-axis, are expressed by the following equation (ASTM E837-08e1, 1996) Eq. 1:

$$
\varepsilon_{\mathrm{r}}=\mathrm{A}\left(\sigma_{\mathrm{x}}+\sigma_{\mathrm{y}}\right)+\mathrm{B}\left(\sigma_{\mathrm{x}}-\sigma_{\mathrm{y}}\right) \cos 2 \theta+\mathrm{C} \tau_{\mathrm{xy}} \sin 2 \theta
$$

where, $\theta$ is the angle of each arbitrary point with respect to the $\mathrm{x}$-axis and $\mathrm{A}, \mathrm{B}$ and $\mathrm{C}$ are constant values called calibration constants. $\sigma_{\mathrm{x}} \sigma_{\mathrm{y}}$ and $\tau_{\mathrm{xy}}$ are the residual stresses trapped in the sample. In Fig. 1, the central whole drilling apparatus and a rosette strain gage are shown.

If the rosette is counterclockwise and the strain gages are located at 0,90 and $225^{\circ}$, then Eq. 2:

$$
\left[\begin{array}{ccc}
\mathrm{A}+\mathrm{B} & 0 & \mathrm{~A}-\mathrm{B} \\
\mathrm{A} & \mathrm{C} & \mathrm{A} \\
\mathrm{A}-\mathrm{B} & 0 & \mathrm{~A}+\mathrm{B}
\end{array}\right]\left\{\begin{array}{c}
\sigma_{\mathrm{x}} \\
\tau_{\mathrm{xy}} \\
\sigma_{\mathrm{y}}
\end{array}\right\}=\left\{\begin{array}{l}
\varepsilon_{1} \\
\varepsilon_{2} \\
\varepsilon_{3}
\end{array}\right\}
$$

The calibration constants A, B and C are dependent on the material properties, geometry of the rosette and the depth of the hole. The important issue of determining the calibration constants can be found by experimental and numerical methods. For isotropic materials $\mathrm{C}=2 \mathrm{~B}$ and for a clockwise rosette $\mathrm{C}$ in Eq. 2 is changed to $-\mathrm{C}$.

By measuring the strains $\varepsilon_{1}, \varepsilon_{2}$ and $\varepsilon_{3}$ and using Eq. 2 , the residual stresses are calculated.

Calibration factors for orthotropic materials: for the two-dimensional cases, five elastic constants $\left(E_{x}, E_{y}\right.$, $\mathrm{V}_{\mathrm{xy}}$ and $\mathrm{V}_{\mathrm{yx}}$ ) are required to relate the stresses and strains in an orthotropic material. When the $\mathrm{x}$ and $\mathrm{y}$ axes lie along the principal elastic directions of the material, Hooke's law generalizes to Eq. 3:

$$
\varepsilon_{x}=\frac{\sigma_{x}}{E_{x}}-v_{y x} \frac{\sigma_{y}}{E_{y}}, \varepsilon_{y}=\frac{\sigma_{y}}{E_{y}}-v_{x y} \frac{\sigma_{x}}{E_{x}}, \gamma_{x y}=\frac{\tau_{x y}}{G_{x y}}
$$

Only four of the five elastic constants are independent due to the following elastic symmetry relationship Eq. 4:

$$
\frac{v_{x y}}{E_{x}}=\frac{v_{y x}}{E_{y}}
$$

To better correlate the residual stresses to the released strains, (Schajer and Yang 1994) defined nine calibration factors for orthotropic materials which can be carried out by closed form, numerical and experimental methods. Using an analytical solution, they calculate the calibration factors for a wide range of mechanical properties of orthotropic materials. They used the following Eq. 5:

$\frac{1}{\sqrt{\mathrm{E}_{\mathrm{x}} \mathrm{E}_{\mathrm{y}}}}\left[\begin{array}{lll}\mathrm{C}_{11} & \mathrm{C}_{12} & \mathrm{C}_{13} \\ \mathrm{C}_{21} & \mathrm{C}_{22} & \mathrm{C}_{23} \\ \mathrm{C}_{31} & \mathrm{C}_{32} & \mathrm{C}_{33}\end{array}\right]\left\{\begin{array}{l}\sigma_{11} \\ \sigma_{12} \\ \sigma_{22}\end{array}\right\}=\left\{\begin{array}{c}\varepsilon_{1} \\ \varepsilon_{2} \\ \varepsilon_{3}\end{array}\right\}$

The compliance terms $\left(\mathrm{C}_{\mathrm{ij}}\right)$ are considered to be non-dimensional using the term $1 / \sqrt{\mathrm{E}_{\mathrm{X}} \mathrm{E}_{\mathrm{y}}}$. Since the $\mathrm{x}$ and $\mathrm{y}$ are the principal elastic directions of the orthotropic material, the terms $\mathrm{C}_{12}$ and $\mathrm{C}_{23}$ become zero.

Simulation of orthotropic materials: In order to simulate the hole drilling process for orthotropic materials, we used the ABAQUS finite element software. For an orthotropic material with the dimensions of 150 $\mathrm{mm}$ by $150 \mathrm{~mm}$, the location of the strain gage and the hole are simulated. 


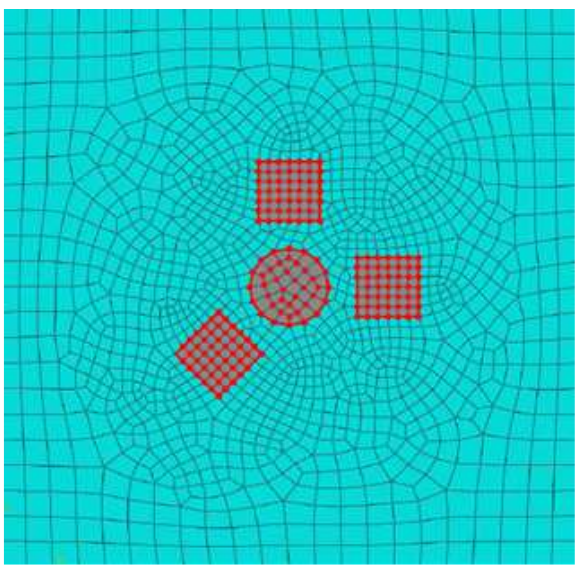

Fig. 2: Mesh of the specimen, rosette and the hole area

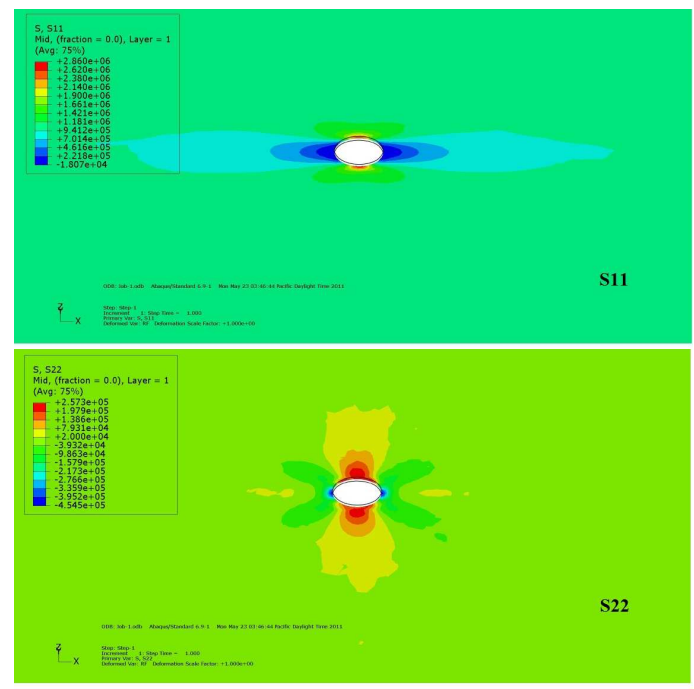

Fig. 3: Stress distribution of an orthotropic composite material due to whole drilling by applying initial stress in $\mathrm{x}$-direction

In the software, we used a second-order eight-node Plane82 solid element. As shown in Fig. 2, the number of elements for the two-dimensional modeling is 4919 and the mesh of the area under the strain gages contains 36 elements.

After applying the initial stress as the residual stress, in order to simulate the whole drilling process, the elements in the area of the strain gage are removed. By knowing the value of the initial stress applied to the model and the released strain on the strain gage area, the calibration factors are calculated. In Fig. 3, the stress distribution of an orthotropic material due to hole drilling by applying stress as the residual stress in $\mathrm{x}$ direction are obtained.
In order to calculate the calibration factors $C_{11}, C_{21}$ and $\mathrm{C}_{31}$, a simulation of the tensile test is implemented by applying a known stress $\left(\sigma_{11}=1, \sigma_{22}=0, \sigma_{12}=0\right)$ in the direction of strain gage number 1 . By measuring the released strains $\varepsilon_{1}, \varepsilon_{2}$ and $\varepsilon_{3}$ using a finite element method and applying Eq. 5, calibration factors $C_{11}, C_{21}$ and $\mathrm{C}_{31}$, are calculated, as follows Eq. 6-8:

$$
\frac{1}{\sqrt{\mathrm{E}_{\mathrm{x}} \mathrm{E}_{\mathrm{y}}}}\left[\begin{array}{lll}
\mathrm{C}_{11} & \mathrm{C}_{12} & \mathrm{C}_{13} \\
\mathrm{C}_{21} & \mathrm{C}_{22} & \mathrm{C}_{23} \\
\mathrm{C}_{31} & \mathrm{C}_{32} & \mathrm{C}_{33}
\end{array}\right]\left\{\begin{array}{c}
\sigma_{11} \\
0 \\
0
\end{array}\right\}=\left\{\begin{array}{c}
\varepsilon_{1} \\
\varepsilon_{2} \\
\varepsilon_{3}
\end{array}\right\}
$$

Also, for measuring the calibration factors $\mathrm{C}_{11}, \mathrm{C}_{21}$ and $\mathrm{C}_{31}$ a simulation of the tensile test is implemented by applying a known stress $\left(\sigma_{11}=1, \sigma_{22}=0, \sigma_{12}=0\right)$ in the direction of strain gage number 3 :

$$
\frac{1}{\sqrt{\mathrm{E}_{\mathrm{x}} \mathrm{E}_{\mathrm{y}}}}\left[\begin{array}{lll}
\mathrm{C}_{11} & \mathrm{C}_{12} & \mathrm{C}_{13} \\
\mathrm{C}_{21} & \mathrm{C}_{22} & \mathrm{C}_{23} \\
\mathrm{C}_{31} & \mathrm{C}_{32} & \mathrm{C}_{33}
\end{array}\right]\left\{\begin{array}{c}
0 \\
0 \\
\sigma_{22}
\end{array}\right\}=\left\{\begin{array}{c}
\varepsilon_{1} \\
\varepsilon_{2} \\
\varepsilon_{3}
\end{array}\right\}
$$

Finally, in order to calculate the calibration factor $\mathrm{C}_{22}$ a simulation of the shear test is performed by applying a known shear stress $\left(\sigma_{11}=1, \sigma_{22}=0, \sigma_{12}=0\right)$ :

$$
\frac{1}{\sqrt{\mathrm{E}_{\mathrm{x}} \mathrm{E}_{\mathrm{y}}}}\left[\begin{array}{lll}
\mathrm{C}_{11} & \mathrm{C}_{12} & \mathrm{C}_{13} \\
\mathrm{C}_{21} & \mathrm{C}_{22} & \mathrm{C}_{23} \\
\mathrm{C}_{31} & \mathrm{C}_{32} & \mathrm{C}_{33}
\end{array}\right]\left\{\begin{array}{c}
0 \\
\sigma_{12} \\
0
\end{array}\right\}=\left\{\begin{array}{c}
\varepsilon_{1} \\
\varepsilon_{2} \\
\varepsilon_{3}
\end{array}\right\}
$$

It is noted that, the strain gages numbered through 1-3 are located in the fiber direction, matrix direction and $45^{\circ}$ with respect to the fiber direction, respectively. If the $\mathrm{x}$ and $\mathrm{y}$ are the principal elastic directions of the orthotropic material, the terms $\mathrm{C}_{12}$ and $\mathrm{C}_{32}$ become zero.

\section{RESULTS}

Validation with published data: In order to compare the results of the hole drilling method with the results presented by (Schajer and Young,1994) a similar component is considered. The mechanical properties of unidirectional glass/epoxy composites are given in Table 1.

For a unidirectional layer of the material presented in Table 1, (Schajer and Young, 1994) offered the following calibration coefficient matrix Eq. 9:

$$
C_{i j}=\left[\begin{array}{ccc}
-0.33 & 0 & 0.15 \\
-0.11 & 0.70 & -0.19 \\
0.19 & 0 & -0.61
\end{array}\right]
$$


Am. J. Engg. \& Applied Sci., 5 (1): 25-28, 2012

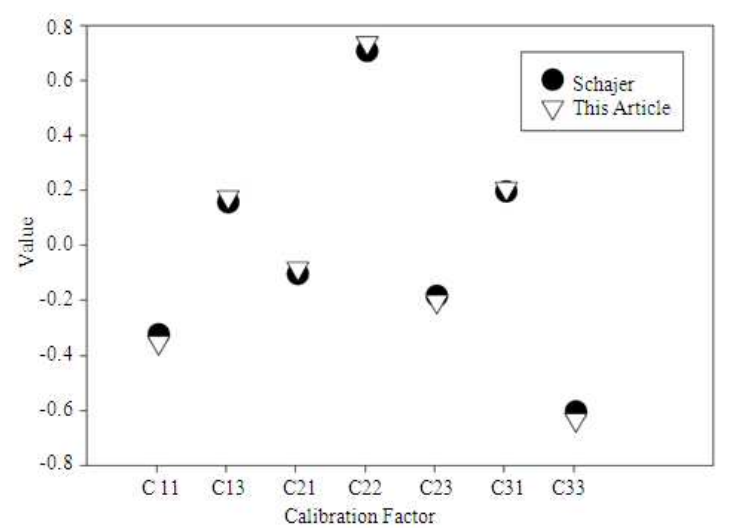

Fig. 4: Result comparison between Schajer and the presents

Table 1: Elastic constants for a unidirectional glass/epoxycomposite

\begin{tabular}{llll}
\hline $\mathrm{E}_{\mathrm{x}}(\mathrm{GPa})$ & $\mathrm{E}_{\mathrm{y}}(\mathrm{GPa})$ & $\mathrm{G}_{\mathrm{xy}}(\mathrm{GPa})$ & $\mathrm{V}_{\mathrm{xy}}$ \\
\hline 25 & 9 & 4.8 & 0.26 \\
\hline
\end{tabular}

The same matrix is achieved by the hole drilling method presented in this study, as follows Eq. 10:

$$
C_{i j}=\left[\begin{array}{ccc}
-0.36 & 0 & 0.17 \\
-0.09 & 0.73 & -0.21 \\
0.20 & 0 & -0.64
\end{array}\right]
$$

\section{DISCUSSION}

A comparison between the results obtained by the two methods have acceptable compliance in the calibration factors.

\section{CONCLUSION}

In the present study, the hole drilling method is simulated by finite element method. The released strains measured by the hole drilling method are converted to residual stresses using calibration factors. In order to calculate the residual stresses for isotropic materials, two calibration factors from released strains are enough. The results obtained in this article show that the released strains in orthotropic materials are different from those of the isotropic materials. In order to determine the residual stresses from the released strains, the simple trigonometric equations available for isotropic materials cannot be used for orthotropic materials. In this research a calibration coefficient matrix of $3 \times 3$ is used. However, for composite materials nine calibration factors are needed. The simulation of the hole drilling process for the orthotropic materials, by Poisson's ratio, shear stiffness and module of elasticity is implemented. The results are compared with the available analytical results. The consistency of the results show the reliability of the modeling process presented in this study. The advantage of the method presented in this research is the capability for modeling or the central hole drilling process. Also different strain gages with different hole diameters can be simulated.

\section{REFERENCES}

ASTM E837-08e1, 1996. ASTM E837 - 08e1 standard test method for determining residual stresses by the Hole-Drilling Strain-Gage method. ASTM International, West Conshohocken, PA.

Bert, C.W. and G.L. Thompson, 1968. A method for measuring planar residual stresses in rectangularly orthotropic materials. J. Comp. Mater., 2: 244-253. DOI: $10.1177 / 002199836800200209$

Mathar, J., 1934. Determination of initial stresses by measuring the deformation around drilled holes. Trans. ASME, 56: 249-254.

Prasad, C.B. and R. Prabhakaran, 1987. Determination of calibration constants for the hole-drilling residual stress measurement technique applied to orthotropic composites-Part II: Experimental evaluations. Comp. Struct., 8: 165-172. DOI: 10.1016/0263-8223(87)90067-5

Schajer, G.S. and L. Yang, 1994. Residual-stress measurement in orthotropic materials using the hole-drilling method. Exp. Mech., 34: 324-333. DOI: 10.1007/BF02325147

Shokrieh, M.M. and A.R. Ghasemi, 2007. Determination of calibration factors of the hole drilling method for orthotropic composites using an exact solution. J. Compos. Mater., 41: 2293-2311. DOI: $10.1177 / 0021998307075443$ 